\title{
Somatosensory Evoked Magnetic Fields in Patients with 'Complete' Cervical Spinal Cord Injury
}

\author{
Masaaki Okada*
}

Department of Rehabilitation Medicine, National Rehabilitation Center for Persons with Disabilities, Japan

\begin{abstract}
Objective: To examine sensory conduction via the spinal cord in patients with clinically 'complete' spinal cord injury.

Design: Case series.

Setting: This research was performed in the rehabilitation hospital for the spinal cord injured persons.
\end{abstract}

Participants: 6 right-handed male patients with complete cervical cord injury who admitted to our hospital to undergo rehabilitation training.

Interventions: Not applicable.

Main Outcome Measures: By measuring somatosensory evoked magnetic fields (SEFs) following tactile stimulation of the limbs, I recorded two sensory conditions from the upper extremities (Median condition) and the lower extremities (Peroneal condition).

Results: In one patient, there were prominent responses in the right primary sensory area (S1) to stimulation applied to the paralyzed left lower extremity (Peroneal condition). In response to stimuli applied to the upper extremities (Median condition), the response latency was longer in 2 patients when their dominant hands were stimulated.

Conclusions: These findings suggest that measuring SEFs for patients with spinal cord injury is useful not only for investigating plasticity of the brain but also for predicting the outcome of training for acquiring the skills of daily life.

Keywords: Somatosensory evoked magnetic fields (SEFs), spinal cord injury, plasticity of the brain.

In patients with complete cervical spinal cord injury, the motor and sensory functions are completely lost below the level of lesion (they belong to ASIA classification A) $[1,2]$. This means they are unable to respond to stimuli in the numb area, which leads to many complications such as pressure sores.

Ioannides et al. [3] reported that cortical activations of S1(primary sensory area) were observed upon electric stimulation of the numb lower extremities in 3 patients with complete thoracic spinal cord injury who had received their injury 3 to 29 years previously. They suggested that the mechanism underlying such sensory conduction might be related to the functioning of remaining spinothalamic tract neurons and spinoreticular projections. It was also proposed that the neurogenic pain below the level of the spinal cord lesion might be conducted via the sympathetic nervous system $[4,5]$.

CNS plasticity, by which damaged nerves regenerate and recover function, can occur only during the relatively early phase following injury.

*Address correspondence to these authors at the Department of Rehabilitation Medicine, National Rehabilitation Center for Persons with Disabilities, 4-1 Namiki Tokorozawa Saitama 359-8555, Japan;

E-mail: qgb02435@yahoo.co.jp
As Ioannides only studied a few patients and other stimulation sites were not investigated, I examined sensory conduction via the spinal cord in 6 patients with clinically 'complete' spinal cord injury by measuring somatosensory evoked magnetic fields (SEFs) following tactile stimulation [6] of the limbs. These 6 patients were in the relatively early phase following injury.

\section{METHODS}

Subjects were diagnosed as having clinically complete quadriplegia due to traumatic spinal cord injuries but were medically stable that they were able to remain still during MEG and MRI examinations. Subjects were 6 right-handed males who were randomly selected from a large pool of patients with complete cervical cord injury admitted to our hospital to undergo rehabilitation training (Table 1). The 'completeness' of spinal cord injuries was confirmed by more than one examiner by performing physical examinations of the subjects and checked their spinal MRI with 2 radiologists (MRI reading blinded). All the patients felt no sensation and had no movement at all below the level of injury. The study protocol was examined and approved by the Ethical Committee of our hospital. In every subject, all details of the study were explained before examinations, and all subjects signed the informed consent form. 
Table 1. Quadriplegic Subjects' Details

\begin{tabular}{|c|c|c|c|c|c|c|}
\hline Patient & $\begin{array}{c}\text { Age } \\
\text { (Years Old) }\end{array}$ & Level & ASIA & $\begin{array}{c}\text { Duration } \\
\text { (Months) }\end{array}$ & Cause & Medication \\
\hline \hline 1 & 28 & C7 & A & 7 & Sports & None \\
\hline 2 & 14 & C6 & A & 13 & Sports & None \\
\hline 3 & 53 & C7 & A & 14 & Fall & None \\
\hline 4 & 26 & C6 & A & 7 & Sports & None \\
\hline 5 & 25 & C7 & A & 5 & Vehicle & None \\
\hline 6 & 23 & C7 & A & 3 & Vehicle & None \\
\hline
\end{tabular}
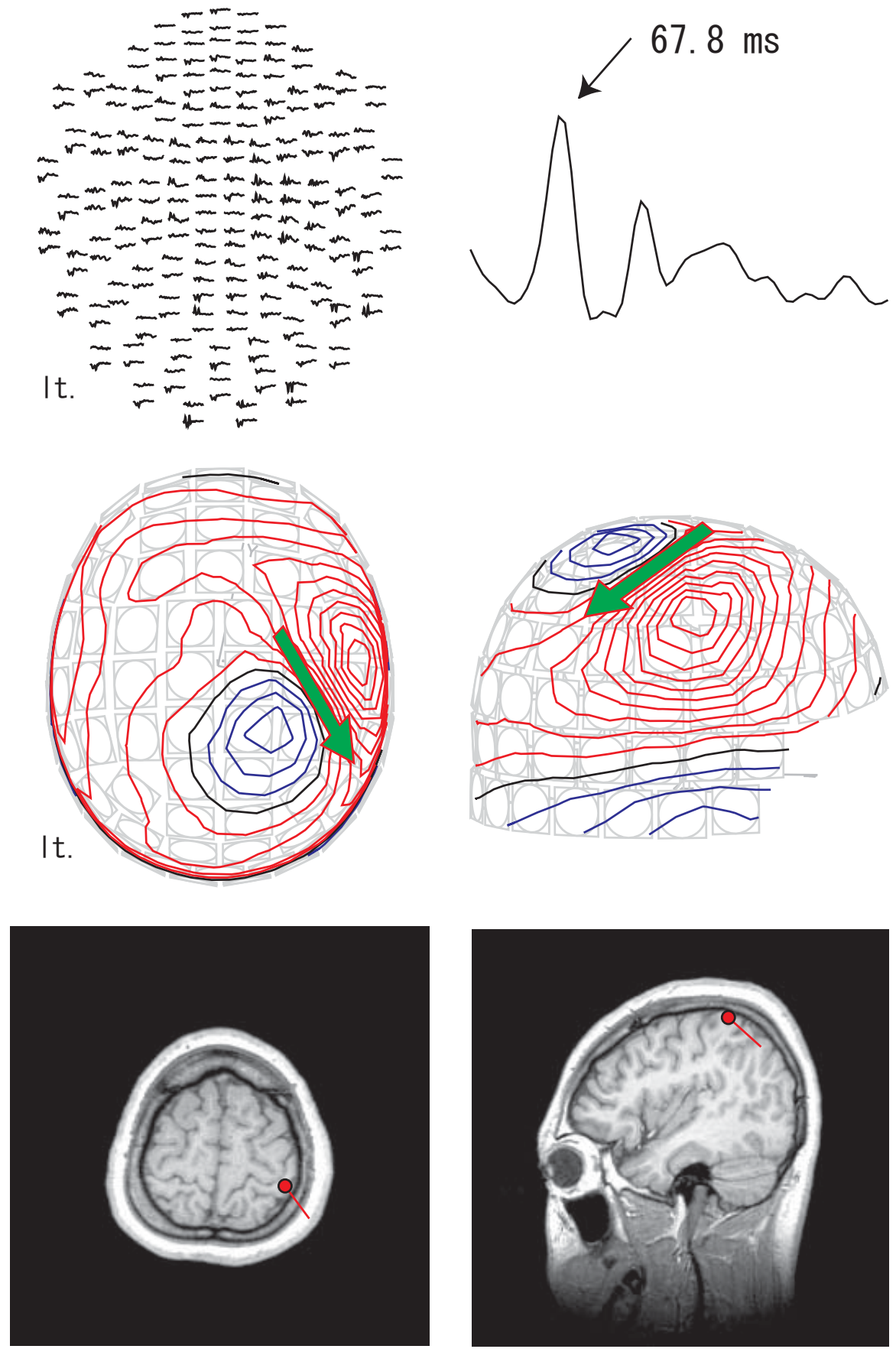

Fig. (1). Patient 2: 1t. median condition: SI response (+).

\section{Measurement}

During the experiment, the patient was sitting in a magnetically shielded room. The head was positioned in a helmet-shaped dewar and tightly pressed against its inner vault. The patient was presented (1) tactile stimuli by the tactile graphic display (KGS) on their index finger (Median condition), (2) the same stimuli on their ankle inside (Peroneal condition) (The sequence of stimulation was as follows: right Median condition, left median condition, right peroneal condition and finally, left peroneal condition). The patients felt the index finger stimulator, since that is above the level of their lesion. Stimulation pressure and frequency were $20 \mathrm{gt}$ and every one second during both conditions. During both
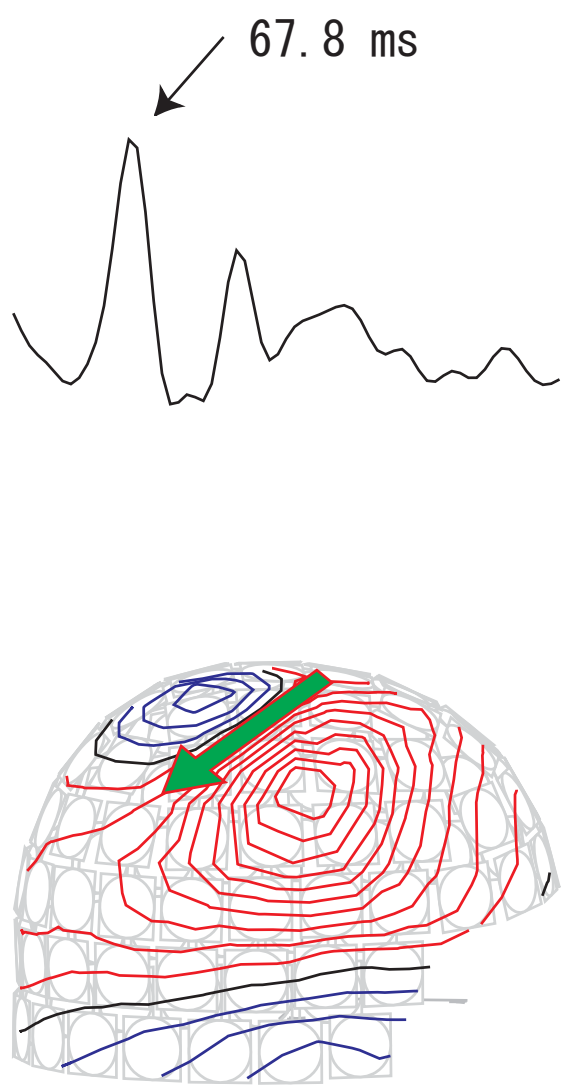
conditions, the patients kept their eyes open and looked at a target $2 \mathrm{~m}$ in front of them.

\section{Data Acquisition}

The magnetic signals of the brain were measured with a helmet-shaped 306-channel neuromagnetometer (NeuromagElekta, Helsinki). To allow alignment of the magnetoencephalogram (MEG) and MRI coordinate systems, the positions of four head position indicator coils with respect to anatomical landmarks were measured with a threedimensional digitizer. At the beginning of each recording
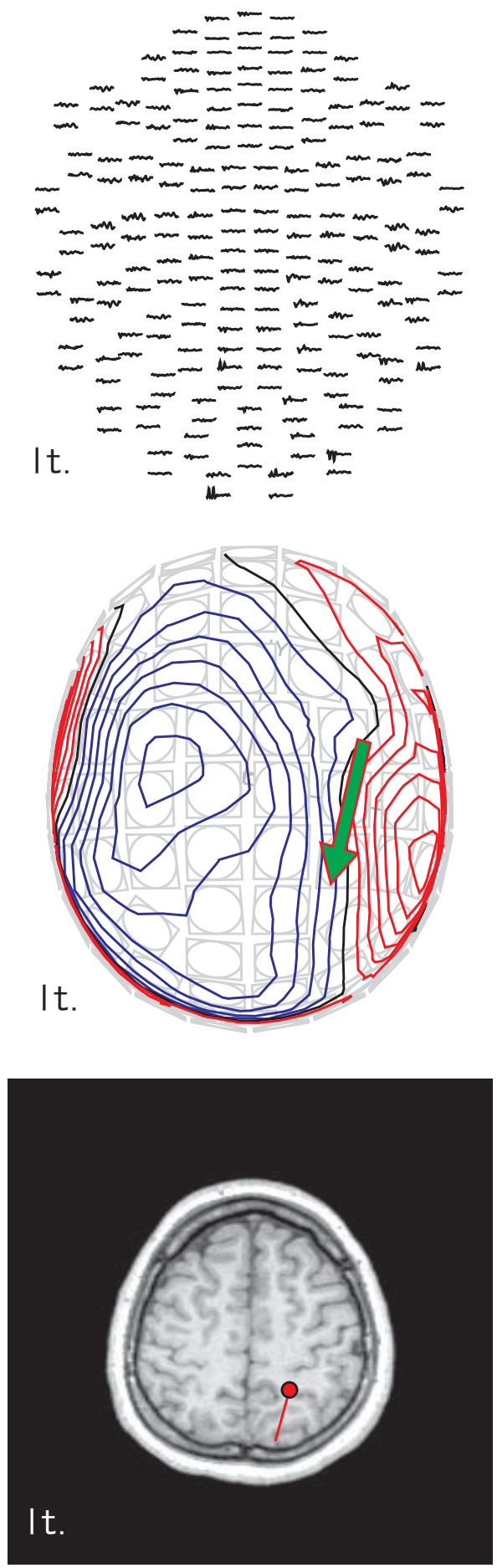

Fig. (2). Patient 2: 1t. peronean condition: SI response (+).

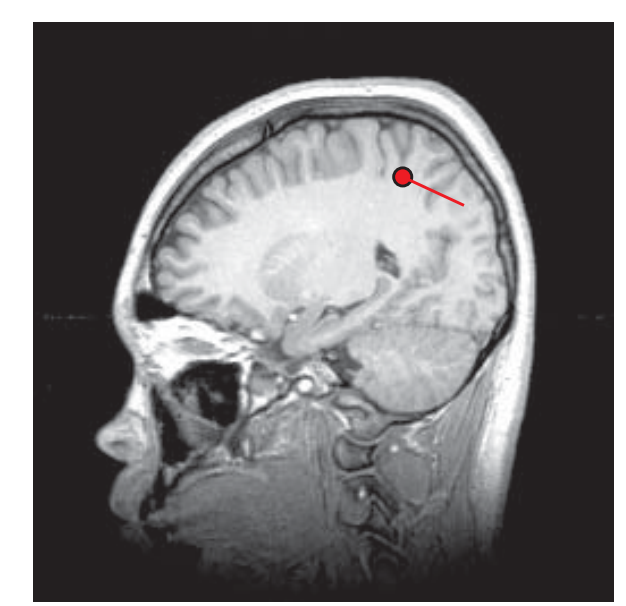

session, the magnetic signals produced by the head position indicator coils on the scalp were measured by the sensors to obtain head position with respect to the sensor array. Head positions were redefined at the beginning of each measurement. Head MRIs were obtained with a 1.5T Siemens Magnetom system (Siemens Medical Systems, Erlangen, Germany). The subject could refresh during short breaks between the stimulations, but he was requested to maintain the head position as stable as possible during the intermissions. The signals from each stimulation were added 150 times and we measured twice in each stimulation to check the reproduction.
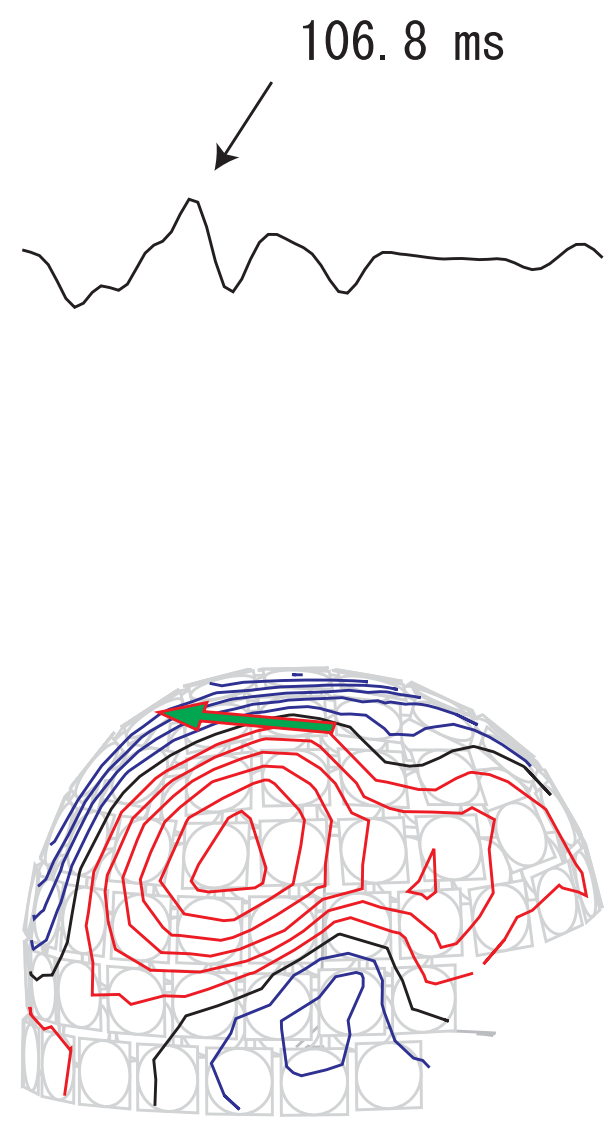


\section{RESULTS}

Figs. $(\mathbf{1}, \mathbf{2})$ shows the MEG signal from Patient 2 in lelt Median condition and left Peroneal condition. The figures show that (1) Median condition showed S1 responses (patients 1-6 were the same), (2) prominent responses, timelocked to the left-foot stimulation, were observed at right primary sensory area(S1) in Patient 2. But the responses were slower than that of healthy adult (50-60 msec [7]).

Each S1 responses of Median condition of Patient 1-6 are shown in Table 2. The Barthel Index is a measure of a person's functioning in activities of daily living (ADL), and 80 points is full score in spinal cord injured patients.

Table 2. S1 Responses of Median Condition and Barthel Index when they were Examined

\begin{tabular}{|c|c|c|c|}
\hline Patient & $\begin{array}{c}\text { rt. Median Stimuli: } \\
\text { S1(msec) }\end{array}$ & $\begin{array}{c}\text { It. Median Stimuli: } \\
\text { S1(msec) }\end{array}$ & $\begin{array}{c}\text { Barthel } \\
\text { Index }\end{array}$ \\
\hline \hline 1 & 68.6 & 70.3 & 80 \\
\hline 2 & 100.6 & 67.8 & 20 \\
\hline 3 & 83.7 & 58.6 & 50 \\
\hline 4 & 63.6 & 65.3 & 50 \\
\hline 5 & 35.2 & 56.9 & 30 \\
\hline 6 & 48.1 & 48.6 & 25 \\
\hline
\end{tabular}

S1: primary sensory area.

\section{DISCUSSION}

In patients who are clinically diagnosed as having complete spinal cord injury, it is uncommon for nerve tracts to be completely severed based on spinal MRI findings. In previous studies [8-10], it has been pointed out that patients with complete spinal cord injury regained signal conduction from numb areas as well as other forms of response suggesting cerebral plasticity. One of 6 patients showed S1 responses to stimuli in the paralyzed and numb lower extremity in the present study. It was unclear whether these responses had been preserved from the time of injury or reappeared at some point over 13 months since the injury, but it may become clear in the future by following up changes in reactions as a function of time.

As shown in Table 2, the response latencies differed between subjects even though their injuries are at the same level of the spinal cord. One of the reasons why subjects 2 and 3 did not reach typical ADL scores obtained by patients with spinal cord injury at C6 level even though more than 1 year had passed since being injured was that their responses to stimuli on the right median nerve were delayed (rt. handedness). In other words, the delayed response of rt. Median condition was related to the degree of ADL acquisition (In subjects 5 and 6 , the B.I. were still low because they were examined only 1 month after the admission to our hospital).

\section{CONCLUSION}

These findings from SEFs only became apparent after subjects were examined using MEG. I propose that this type of examination is useful not only for investigating plasticity of the brain but also for predicting the outcome of training for acquiring the skills of daily life.

\section{REFERANCES}

[1] Ditunno JF, Jr. The international standards booklet for neurological and functional classification of spinal cord injury. Am Spin Injury Assoc Paraplegia 1994; 32: 70-80.

[2] Maynard F. International standards for neurological and functional classification of spinal cord injury. Spinal Cord 1997; 35: 266-74.

[3] Ioannides A. Brain activation sequences following electrical limb stimulation of normal and paraplegic subjects. Neuroimage 2002; 16: 115-29.

[4] Green JB. Cortical sensorimotor reorganization after spinal cord injury: an electroencephalographic study. Neurology 1998; 50: $1115-21$.

[5] Green JB. Cortical motor reorganization after paraplegia: an EEG study. Neurology 1999; 53(4): 736-43.

[6] Hari R. Somatosensory evoked magnetic fields from SI and SII in man. Electroencephalogr Clin Neurophysiol 1984 ; 57: 254-63.

[7] Hari R. Time-varying activation of different cytoarchitectonic areas of the human SI cortex after tibial nerve stimulation. Neuroimage 1996; 4: 111-8.

[8] Foltys $H$. The representation of the plegic hand in the motor cortex: a combined fMRI and TMS study. Neuroreport 2000; 11: 147-50.

[9] Lotze M. Reorganization in the primary motor cortex after spinal cord injury-A functional Magnetic Resonance (fMRI) Study. Restor Neurol Neurosci 1999; 14: 183-7.

[10] Bruehlmeier M. How does the human brain deal with a spinal cord injury? Eur J Neurosci 1998; 10: 3918-22. 